DOI: http://dx.doi.org/10.14393/che-v15n1-2016-10

\title{
Os primeiros tempos de escola evangélica-luterana em Lomba Grande/RS (1834-1881)
}

The beginning period of the Evangelical Lutheran school in Lomba Grande, RS, Brazil (1834-1881)

Los primeros tiempos de la escuela evangélica-luterana en Lomba Grande/RS

$$
(1834-1881)
$$

\author{
JOSÉ EDIMAR DE SOUZA ${ }^{1}$ \\ LUCIANE SGARBI SANTOS GRAZZIOTIN ${ }^{2}$
}

\section{Resumo:}

A comunidade de Lomba Grande é uma localidade que foi colonizada, principalmente, por imigrantes alemães. O culto evangélico desses imigrantes contribuiu para instalação da Igrejaescola neste lugar. Nesse sentido, o objetivo é compreender o modo como esta comunidade instituiu e desenvolveu o processo de escolarização, no decorrer do século XIX. Sob a perspectiva teórica da História Cultural o estudo analisa documentos referentes a história da instituição, narrativas de jornais e documentos pessoais de docentes. Como análise destaca-se que a escola, na segunda metade deste século, passou acolher alunos de outros grupos sociais, não apenas imigrantes alemães e assumiu um caráter comunitário, público. Identifica-se que, além do auxílio que as famílias dos alunos realizavam, a escola era mantida com recursos governamentais de subvenções.

Palavras-chave: Escola comunitária. Ensino Primário. Aula Pública.

\footnotetext{
${ }^{1}$ Doutor em Educação, com estágio de pós-doutorado realizado na Unisinos. Professor substituto de Ensino de História na Universidade Federal da Fronteira Sul, Campus de Erechim/RS. E-mail: profedimar@gmail.com

${ }^{2}$ Doutora em Educação pela Pontifícia Universidade Católica do Rio Grande do Sul, com período sanduíche na Universidade de Lisboa. Professora do Curso de Pedagogia e pesquisadora do Programa de Pós-Graduação em Educação da Unisinos. E-mail: 1sgarbi@unisinos.br
} 


\begin{abstract}
:
The community of Lomba Grande is a town that was settled mainly by German immigrants. The evangelical worship of these immigrants contributed to installation of the church-school in this place.In this sense, the objective is to understand how this community has established and developed the educational process in the course of the nineteenth century. Under the theoretical perspective of Cultural History, the study examines documents relating to the history of the institution, narratives newspapers and personal documents of teachers. We highlight that the school, in the second half of this century, it began welcoming students from other social groups, not just German immigrants and assumed a community character, public. It is identified that, in addition to aid the families of the students performed, the school was maintained with government funding grants
\end{abstract}

Keywords: Community School. Primary Teaching. Public School.

\title{
Resumen:
}

La comunidad de Lomba Grande es una localidad colonizada principalmente por inmigrantes alemanes. El culto evangélico de estos inmigrantes contribuyó para la instalación de la iglesia-escuela en esta ubicación. En este sentido, el objetivo es comprender cómo esta comunidad ha establecido y desarrollado el proceso educativo en el curso del siglo XIX. Bajo la perspectiva teórica de la Historia de la Cultura, el estudio examina los documentos relativos a la historia de la institución, artículos de periódicos y documentos personales de los maestros. Como análisis enfatiza que la escuela, en la segunda mitad de este siglo, empezó a recibir alumnos de otros grupos sociales, no sólo los inmigrantes alemanes y asumió un carácter comunitario, público. Se identifica que, además de la ayuda que las familias de los estudiantes proveían, la escuela se mantuvo con fondos de subvención del gobierno.

Palabras clave: Escuela de la Comunidad. Educación primaria . La escuela pública. 


\section{Introdução}

A História pretende compreender tanto as uniformidades e as regularidades de formações sociais quanto as tensões e diferenças que se materializam no embate das ações humanas. O passado humano, aos olhos investigativos do pesquisador, não pode ser entendido como um conjunto de ações isoladas, portanto, “[...] o processo histórico constitui-se dessas práticas, ordenadas e estruturadas de maneiras racionais”. (BEZERRA, 2005, p. 43). A análise de documentos, por exemplo, auxilia no propósito de ampliar o campo que se problematiza e serve, da mesma forma, como ponto de partida para se entender esses processos. A construção do processo de constituição dos primeiros tempos de escola ${ }^{3}$, em Lomba Grande, considera as práticas estabelecidas por este grupo local, especialmente formado por imigrantes alemães ${ }^{4}$.

No início do século XIX, os imigrantes alemães, em grande parte evangélicosluteranos $^{5}$, também abriram caminhos e fundaram as primeiras escolas. Isso aconteceu em Lomba Grande que até 1940 pertencia politicamente ao território de São Leopoldo. Lomba Grande é atualmente um bairro do município gaúcho de Novo Hamburgo, situado na região Sul do Brasil, como se observa abaixo, na figura 1.

Figura 1 - Novo Hamburgo no Rio Grande do Sul.



Fonte: Souza (2015, p. 22).

\footnotetext{
${ }^{3}$ Quanto ao conceito construído de escola teuto-brasileira cabe refletir que a mesma não é uma instituição homogênea. (BAADE, 2012). Santos (2012), apoiado em Schaden entende que elas se constituam de pelo menos três modos: as escolas alemãs, as comunitárias ou coloniais e as mantidas pelas congregações religiosas alemãs.

${ }^{4}$ Uma primeira versão deste texto foi apresentada no $19^{\circ}$ Encontro da Associação Sul-Rio-Grandense de Pesquisadores em História da Educação - ASPHE/RS, em Pelotas, de 06 a 08 de novembro de 2013.

${ }^{5}$ A expressão "evangélico-luterano" refere-se ao termo "evangélico", utilizado pelas próprias lideranças e comunidades em publicações da época e na tradição oral. Que será identificado apenas como evangélica nesta escrita. Rambo (2002) acrescenta que foi a Igreja Protestante Alemã aquela trazida pelos imigrantes em 1824, e que mais tarde se tornaria conhecida com o nome de Igreja Evangélica de Confissão Luterana. Mas, a partir de 1900, implantou-se também a Igreja Luterana do Brasil, vinculada ao Sínodo de Missouri.
} 
Neste lugar, como nas mais diferentes localidades rurais de ocupação colonial europeia, no Rio Grande do Sul, a forma original da escola foi aquela de cunho religioso ou da própria comunidade. O caráter organizativo e constitutivo das práticas e processos escolares, entre o século XIX e início do século XX, tem procurado estruturar e mapear as inúmeras iniciativas de institucionalização da escola primária. (SOUZA, 2011). A instrução pública ${ }^{6}$ primária tem despertado interesse de diferentes disciplinas científicas com especial interesse da historiografia da educação atual e de perspectiva cultural.

No caso brasileiro, será a partir do século XIX que, marcadamente, ocorre a “[...] progressiva institucionalização da escola e lenta afirmação do lugar do Estado como principal provedor da educação.”. (LOPES; GALVÃO, 2001, p. 22). A escola, como espaço qualificado para este fim, não existiu desde sempre, como argumentam Viñao Frago e Escolano (2001), pois a instituição ${ }^{7}$ só merece tal nome quando se instala e se realiza em um lugar específico. Um aspecto desencadeador deste processo é a institucionalização da educação como tarefa do Estado, no transcorrer do século XIX e início do XX, que se identifica timidamente em nossa investigação.

\section{A pesquisa documental sob a ótica da História Cultural}

Gruzinski (2003) problematiza o modo como a pergunta de pesquisa é elaborada em investigações sob a ótica da História Cultural. O questionamento, diante das fontes, permite refletir sobre as distintas possibilidades de análise de um mesmo documento. Nesse sentido, a localização de documentos, referentes à Aula Pública ${ }^{8}$ da Lomba Grande, que em outra pesquisa, permaneceu "truncada" quanto a sua relação com a escola da comunidade evangélica e recebeu novos significados diante da identificação de outros documentos semelhantes, como: mapas de frequência escolar; registros de concursos de professores normalistas para a região; documentos pessoais do professor Henrique Meyer, etc.; cujos detalhes podem ser conferidos em Souza (2012-2015).

\footnotetext{
${ }^{6}$ Público, nesse contexto, é de aberto ao público, em contraposição à educação doméstica. (MENDONÇA, 2010, p. 43). Neste estudo se observa os primórdios de constituição de uma escola pública do Estado, como atenta, por exemplo, Saviani (2010).

${ }^{7}$ Saviani (2007), apoiado na definição de Torrinha, apresenta pelo menos quatro acepções para a etimologia da palavra "instituição". Utiliza-se aqui a identificada como construção coletiva em torno de determinados procedimentos que significam e orientam as práticas de um grupo específico.

${ }^{8}$ Trata-se de dois documentos (1863 e 1866), recuperados em 2011, no acervo pessoal de Moisés Braun e traduzidos do "alemão gótico" pelo professor Dr. Martin Dreher (SOUZA, 2012). Em 2013, localizou-se, no Arquivo Visconde de São Leopoldo, outro documento semelhante a este, concedido ao aluno Bernhard Winter pelo professor Meyer, em 13 de novembro de 1862.
} 
A história, por ser uma prática, não é a simples fala nobre de uma interpretação desencarnada e desinteressada, pelo contrário, ela é sempre mediatizada pela técnica, pelas lentes curiosas do investigador no processo de transformação entre o documento e sua construção. (DOSSE, 2004). A prática da pesquisa histórica vai além do estudo das ações dos homens pertencentes aos círculos do poder civil, religioso e militar, etc. Ela também inclui testemunhos anônimos, deixados por todos aqueles que interagem e negociam, direta e indiretamente, com as diferentes esferas sociais (BORGES, 2011).

A necessidade de se adensar o campo investigativo das temáticas que se dedicam aos estudos das chamadas "culturas escolares", e o seu avanço neste campo, tem permitido adentrar à "caixa preta" da escola e "desnaturalizar" a instituição escolar, reconstruindo-a historicamente, realizando uma discussão de forma articulada dos "[...] tempos, espaços, sujeitos, materiais e conhecimentos envolvidos naquilo que alguns têm chamado de processo de escolarização da sociedade" (FARIA FILHO; VIDAL, 2003, p. 39).

Sob a ótica da História Cultural, esboça-se aqui a tentativa de caracterizar uma visão própria de escola construída pela comunidade de Lomba Grande ${ }^{9}$, suas singularidades e semelhanças, no modo de organização e estruturação do ensino primário, das práticas construídas, em especial para que fosse possível ler, escrever e contar.

As práticas educativas de sujeitos escolares, envolvidos nesse processo, são analisadas nas suas relações e interfaces com os aspectos sociais e culturais, que permitem compreender os tempos e espaços escolares na dinâmica de constituição dos processos educativos.

Partindo-se da análise documental, buscou-se identificar o modo como, em diferentes lugares e momentos, uma determinada realidade social é construída a partir do entrecruzamento de aspectos que emergiram de sua análise. O uso de documentos em pesquisa possibilita ampliar o entendimento de objetos e a dimensão do tempo à compreensão do social cuja compreensão necessita de contextualização histórica e sociocultural. (CELLARD, 2008). Além disso, a análise cuidadosa deve colocar em questão suas condições de produção. Gil (2010), apoiada em Chartier, complementa que nenhum texto mantém uma relação transparente com a realidade, já que há de se considerar as relações e circunstâncias de sua construção, enquanto possibilidade interpretativa.

\footnotetext{
${ }^{9}$ Nesse sentido, é importante ressaltar que, em Lomba Grande, a relação híbrida no modo em que a escola comunitária se constitui possibilitou que, além dos imigrantes alemães, outros moradores da localidade se beneficiassem da instituição de ensino, instalada pelos colonizadores. Um outro estudo, que pode elucidar melhor este aspecto, pode ser conferido em Souza e Grazziotin (2015).
} 


\section{Os primeiros tempos de escola da comunidade evangélica-luterana}

A escola da comunidade evangélica de Lomba Grande, construída no século XIX, está inserida no contexto da história da imigração alemã em São Leopoldo, município que atualmente faz limite geográfico com Novo Hamburgo. Esta modalidade institucional contribuiu para que se construíssem culturas escolares neste lugar. Müller (1984, p. 36) argumenta que "[...] ainda não foi escrita em letras douradas" uma história das "Gemeindeschule", escolas de comunidades religiosas, reconhecidas como marco básico na colonização dos imigrantes alemães. Além disso, apresenta, na sua obra "Colônia Alemã 160 anos de história", resenha histórica da Comunidade Evangélica de Lomba Grande, "única que tenho conhecimento [...] escrita em 1948, pelo então pároco Jacob Sauer", (MULLER, 1984, p. 28). Ainda quanto às fontes citam-se as narrativas publicadas no jornal "O 5 de Abril”, de 1948, bem como ofícios e correspondências localizados no Arquivo Visconde de São Leopoldo.

O legado educacional destas instituições tem sido estudado, principalmente por Kreutz (1991, 1994, 2000, 2002, 2005, 2010a, 2010b), Rambo, (1994, 2002), Arendt (2008), Dreher (2008) para citar pesquisadores cuja investigação se aproxima desta, considerando que tem as escolas alemãs como objeto de estudo, mesmo que a proposta teórica e metodológica seja diferenciada. De modo geral, os estudos de Seyferth (2012) e Schelbauer (2009) procuram ampliar a discussão em nível nacional, bem como desdobrar a temática que, nos últimos anos, tem se inclinado para uma discussão mais antropológica e cultural, como também propõem Santos (2012) e Baade (2012).

Rambo (2002) acrescenta que a profunda religiosidade dos imigrantes europeus desempenhou um papel fundamental na fisionomia sociocultural da população imigrante no Brasil e que também produziu efeitos no modo como se organizaram as primeiras escolas nos núcleos coloniais.

Os imigrantes estavam habituados à existência de um sistema escolar bastante satisfatório em sua terra de origem. Como o governo Imperial não implantou escolas nas regiões de imigração dos alemães, os próprios colonos se organizaram, criando e sustentando as suas escolas. Esta característica indica a ênfase dada à questão escolar pelos imigrantes alemães que "[...] insistiam fortemente na mesma, de modo que sua iniciativa se tornou singular para o contexto do país" (KREUTZ, 1994, p. 150). 
Na esfera nacional, o início do século XIX é marcado também pela aprovação da primeira Lei das Escolas de Primeiras Letras, em 1827, e que orientava implantação de instrução primária gratuita que deveria ser estendida por todos os cidadãos. Segundo Saviani (2010), o objetivo era ensinar a população a ler, escrever, as quatro operações, prática de quebrados, decimais e proporções, as noções mais gerais de geometria prática, a gramática da língua nacional, os princípios de moral cristã e de doutrina da religião católica. Mas esta lei não chegou a ser efetivada, pois o Ato Adicional de 1834 colocou o ensino primário sob a jurisdição das províncias.

Na segunda metade do século XIX, começam a surgir as primeiras escolas públicas de instrução primária, seguindo os moldes das práticas e da organização do município da Corte. A instrução pública garantiria elevada aspiração patriótica, moralidade, bem-estar dos cidadãos e desenvolvimento de uma elite de acúmulo dos "maiores cabedais" (BOTO, 2010).

A partir de 1850, o discurso a favor da difusão da escola primária, como função do Estado, foi tomando força e ganhando adeptos dentro e fora do parlamento brasileiro, em projetos de reforma, decretos, regulamentos, relatórios, discursos e escritos diversos (SCHELBAUER, 2009). As reformas Couto Ferraz (1854) e Leôncio de Carvalho (1878) não mudaram, durante o Império, o panorama deixado pelas reformas pombalinas (INÁCIO FILHO E SILVA, 2010). Dessa forma, as escolas isoladas e o descaso com a instrução pública definiram o cenário inicial do período republicano no Brasil. Não havia um processo de institucionalização da escolarização para o conjunto da população por parte do Estado ${ }^{10}$, o que favoreceu as iniciativas particulares (CORSETTI; LUCHESI, 2010). Quando do início da Revolução Farroupilha a Instrução Pública estava em total atraso e havia um total de quarenta e quatro aulas de primeiras letras cuja prática pedagógica se baseava no método Lancaster ou de ensino mútuo (XAVIER, 2008).

Valle e Arriada (2012) argumentam que, apesar deste contexto desfavorável para instrução, há registros da atuação de diversos mestres nas Vilas, ministrando aulas de primeiras letras. Em 1814, com a criação do subsídio literário, as primeiras aulas são projetadas e, em 1820, iniciaram as primeiras nomeações de professores para as cadeiras das Aulas de Primeiras Letras. A estatística da instrução pública, do governo provincial do Estado

\footnotetext{
${ }^{10}$ Quanto às políticas educacionais, Corsetti e Luchesi (2010) citam o denso estudo de Elomar Tambara e Eduardo Arriada e que recuperam os diferentes regulamentos deste período. Aqui nos interessa a menção feita: a Lei 14 - Lei de Instrução Primária (1837); Regulamento para as Escolas Públicas de Instrução Primária (1842); Regulamento Para a Instrução Primária e Secundária da Província de São Pedro do Rio Grande do Sul (1857); Regulamento de Instrução Pública alterando o Regulamento de Instrução Pública de 1857/ (1859); Regulamento da Instrução Pública Primária (1876); Regulamento da Instrução Pública (1876).
} 
do Rio Grande do Sul, apresentada por Petry (1923), indica que, em 02 de agosto de 1827, a primeira aula foi instalada em Porto Alegre. E em 1828 foram criadas vinte e oito escolas para o sexo masculino e o sexo feminino. Porém, em 1832, funcionava uma para o sexo feminino e seis para o sexo masculino. Este número salta para noventa e duas escolas, frequentadas por 3543 alunos, em 1852, ocasião em que a instrução pública do Rio Grande do Sul encontravase em evidência no contexto nacional, ocupando a quinta posição no ranking das províncias brasileiras, perdendo para Minas Gerais, Rio de Janeiro, Bahia e São Paulo. Braun (2012), sobre as aulas públicas na Vila de São Leopoldo, indica que havia apenas três aulas de língua vernácula do governo em 1846, conforme relatório do Dr. Hillebrand, enquanto vinte e seis eram particulares e ministradas em alemão. Kreutz (1994) indica que quinze eram comunitárias e em duas lecionavam professores contratados pelo governo. A manifestação do vereador João da Silva Paranhos, cuja proposta fora apresentada à sessão plenária da vereança, em 1847, sugeria que

[...] a Instrução pública deve ser obrigatoria a todos os Pays de familia a fazerem seus filhos frequentar as Escollas do Idioma Nacional, sem que possão ser addmittidos em insinuação de outro Idioma sem que saibão ler, [...] escrever, e pelo menos saberem as quatro operações d'Arithmetica da linguagem do Paiz e que nas Escollas particulares [...] que tem os Professores publicos de hírem á Missa com os seus Alumnos tenhão igualmente os Mestres particulares [...]. (SÃO LEOPOLDO, 1847, p. 218) ${ }^{11}$.

A ata da sessão plenária dos vereadores da Vila de São Leopoldo, em 1847, acentua o valor significativo que tinha a instrução para o município. Evidencia o "padroado" e sugere que as práticas dos professores públicos, em aulas particulares, fossem equiparadas ao trabalho dos professores das aulas públicas.

No que se refere ao currículo desta escola de "improviso", a instrução era dada em alemão, pelo menos parcialmente, porque poucos eram os professores que, como recémimigrados, entendiam o português (RAMBO, 1994). Nas primeiras escolas-capela, que geralmente eram casas muito rudimentares, cantava-se, rezava-se e se lia palavras da Bíblia (DREHER, 1993). A frequência escolar geralmente não ultrapassava três anos, pois não havia um limite de idade para ingressar na escola (MÜLLER, 1978).

\footnotetext{
11 Tratando-se de pesquisa em história da educação, optou-se em preservar a originalidade de escrita.
} 
Para Dreher (1993), com a escola-igreja surge também um espírito de "comunitarismo", ou seja, reforçava-se o pronome "nossa" cuja prática social fazia com que cada comunidade se constituísse em micro representação da Igreja isolada e autônoma. Este aspecto se preservou em muitas regiões rurais até os anos $1860^{12}$, momento que Kreutz (2002) caracteriza como de maior atenção do Estado e da Igreja no processo escolar da escola básica.

Esta escola era de primeiras letras e multisseriada, diferenciando-se daquela proposta pelo protestantismo de missão que pretendia atingir as elites brasileiras. As Aulas, neste distrito rural, situavam-se na sede, região central e, posteriormente, foram instaladas nas demais localidades do interior. A partir dos documentos organizados, foi possível construir um quadro demonstrativo que evidencia a presença dos professores contratados ${ }^{13}$, entre 18341939, como segue:

Quadro 1 - Demonstrativo: professores e pastores (1834-1939)

\begin{tabular}{|l|l|l|l|}
\hline Professores & Pastor & Período & Fonte \\
\hline $\begin{array}{l}\text { João Michel Paul } \\
\text { Gaspar }\end{array}$ & P. Johann Georg Ehlers (1824-1842) & $\begin{array}{l}1842- \\
1846\end{array}$ & $\begin{array}{l}\text { Müller (s/a); } \\
\text { Müller (1984) }\end{array}$ \\
\hline Wilhelm Gälzer & $\begin{array}{l}1842-1860(?) \\
\text { P. August Wilhelm Klenze (1860-1861) }\end{array}$ & $1846-$ & Müller (1984) \\
\cline { 1 - 2 } $\begin{array}{l}\text { Henrique Meyer } \\
\text { (1860 a 1881) }\end{array}$ & $\begin{array}{l}1861-1864 \text { (vago) } \\
\text { P. Häsbert de H. Velho e P. Recke de Campo Bom }\end{array}$ & $1860-$ & Souza (2012); \\
\cline { 2 - 2 } & P. Dr. Hermann Borchard (1864 - 1870) & \multirow{3}{*}{ Müller (1984) } \\
\cline { 2 - 2 } & P. Carl Friedrich Wegel (1870-1873) & & \\
\cline { 2 - 2 } & P. Häuser (1873-1874) & & \\
\hline
\end{tabular}

Fonte: Elaborado pelo autor, 2013.

A escola da Comunidade Evangélica foi fundada em 08 de fevereiro de 1842 e sabe-se que funcionava desde 1834, em um antigo prédio, e que também servia às pregações dos "cura de almas". Antes existia uma construção que servia como escola e igreja, chamada "igreja de barro" "Lehmkirche". No ano de 1835, a construção dessa capela-escola iniciou, porém não foi possível terminá-la pela inquietação da Guerra Farroupilha. Somente em 1842 a construção ficou pronta e foi inaugurada pelo Pastor Ehlers (MÜLLER, 1984).

Um prédio de alvenaria e mais adequado para a igreja foi construído apenas em 1848 e a igreja primitiva foi substituída ${ }^{14}$ e esta parece ser a data considerada para retratar a história da

12 Kreutz (2000) destaca a participação dos "Brummer", entre 1860 e 1870, que representaram um "fermento" para o desenvolvimento material e cultural entre os imigrantes. Este apelido se deve ao fato de serem questionadores, pois faziam "zunido". Inicialmente foram contratados pelo Império para lutar na Guerra contra Rosas, em 1852.

${ }^{13}$ A partir de 1915 os professores serão também os pastores e a escola.

14 "Como lembrança valiosa da festa, foi exposto à venda um fascículo ricamente ilustrado em ótima impressão, contendo uma resenha histórica da vida da comunidade, bem como numerosas fotografias oferecidas 
Comunidade Evangélica Luterana. É provável também que tenham atuado professores leigos antes de 1842. O primeiro professor, e que atuava na antiga construção da Igreja, foi João Michel Paul-Gaspar, entre 1842 a 1846.

Entre 1846 a 1860 o professor foi Wilhelm Gälzer e entre 1860 a 1881 Henrique Meyer. Na década de 1860, a velha "escola de barro" não atendia mais as necessidades e Meyer teve que dar aulas na igreja; então, a comunidade se viu obrigada a construir um prédio para a escola (MÜLLER, 1984). Este período coincide com os ofícios e correspondências, localizadas no Arquivo Visconde de São Leopoldo.

Tudo indica que, a partir de 1862, a escola comunitária tenha se transformado em Aula Pública, como registra o prêmio escolar concedido por Meyer a um aluno. Além disso, em 12 de março de 1866, o Inspetor Geral da Instrução Pública, em Porto Alegre, solicita ao Delegado da Instrução de São Leopoldo que seja realizada inspeção nas aulas do idioma do país e destaca as Aulas Públicas da Lomba Grande.

A partir dos dados ${ }^{15}$ organizados sobre as subvenções destinadas à aula isolada, compreende-se que havia pelo menos duas práticas de gestão deste recurso público. A primeira refere-se àquela encaminhada diretamente às Câmaras municipais e a gestão fica a cargo do próprio governo municipal, fiscalizado pela vereança. A segunda era aquela cujo erário encaminhava-se diretamente ao professor, ora encaminhada via governo municipal, ora destinado diretamente ao docente que recebia na coletoria pública.

Estas duas práticas contemplaram a escola da comunidade evangélica de Lomba Grande, principalmente com recursos como o pagamento de aluguel do prédio e posteriormente com o pagamento do erário dos docentes. Para Willems (1980) a subvenção financeira certamente foi fundamental, na medida em que muitas escolas comunitárias eram mantidas com as mensalidades pagas pelos seus membros.

O professor Meyer iniciou como professor de uma aula do sexo masculino que posteriormente se tornou mista, o que era comum acontecer em regiões rurais, na falta de professores habilitados. A partir de 1862, o professor Henrique Meyer promove listas para a

pelo sr. Germano Stumpf [...] proprietário de um conhecido atelier fotográfico em S. Leopoldo". (O 5 de Abril, 1948 , p. 3). Acredita-se que se trata do material transcrito por Müller (1984), contudo ainda não foi localizado nenhum exemplar deste documento.

${ }^{15}$ Analisaram-se as folhas de pagamento de professores públicos das aulas federais, estaduais, municipais, isoladas e subvencionadas entre 1890 a 1950, no Arquivo Público do Rio Grande do Sul. Mais detalhes sobre as subvenções em Lomba Grande em Souza (2015). 
construção de uma escola e mais duas peças que pudessem servir de moradia dos professores. Em 1864 a construção estava pronta, como se observa na Figura 2, abaixo:

Figura 2 - Casa Pastoral e Escola Comunitária de Lomba Grande

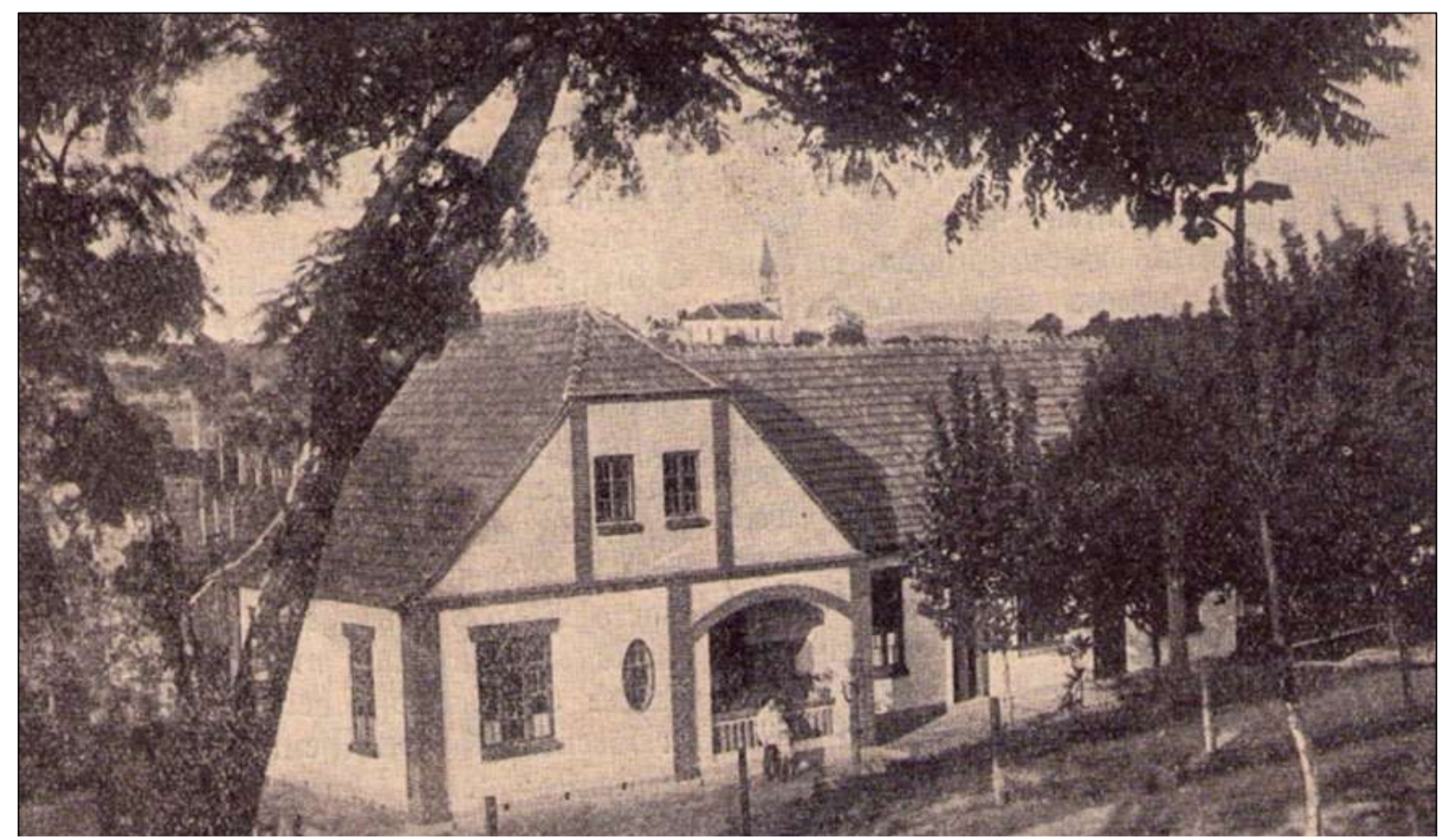

Fonte: NOVO HAMBURGO, 1928, p.1.

Em 1890 foram acrescentados mais dois quartos ao prédio que, a partir de 1915, passou a abrigar a Casa Pastoral ${ }^{16}$. As Aulas, organizações institucionais que foram pioneiras das escolas primárias da atualidade, nas palavras de Gil e Caldeira (2011), caracterizaram o cenário educacional entre os séculos XIX e início do XX, instaladas em espaços urbanos, rurais e distritais.

\section{Considerações finais}

O modo inicial de organização destas escolas comunitárias, em algumas localidades, preservou-se até meados do século XX. Para Kreutz (2005), esse processo não foi homogêneo, já que as singularidades, referentes à permanência e/ou transformação deste modo de "improviso", que permeava a estrutura das escolas teuto-brasileiras, ainda carecem

\footnotetext{
${ }^{16}$ Em 2011 foi adquirida pela Prefeitura Municipal de Novo Hamburgo. Atualmente funciona como um espaço cultural sob o nome de "Casa da Lomba".
} 
de ser aprofundadas. Em Lomba Grande, ocorreu um processo híbrido quanto à instituição das práticas e disseminação de uma cultura de escolarização, resultado de um processo que articulou valores comunitários de diferentes grupos sociais, étnicos e as relações de contexto, sócio, político e cultural (SOUZA, 2015).

Historiar o processo de institucionalização de escolas, nesse bairro, é compreender e explicar os processos e os compromissos sociais como condição instituinte (MAGALHÃES, 2004), aspecto que necessita transcender entendimento que corresponde não apenas à instalação da escola da Comunidade Evangélica-luterana, ou seja, é percebê-la como elemento cultural subjetivo que possibilitou construção de um processo de manifestação cultural que Certeau (2012) chama de "autonomia no nível cultural", uma forma de simbolizar a materialidade organizativa desse grupo social.

Investigar a escola primária em Novo Hamburgo, especialmente a presença do ensino público em regiões rurais de colonização germânica, é reconhecer o processo e evolução do sentido que o público adquire no sistema de governo republicano (SAVIANI, 2010). Além disso, se a alfabetização, com os imigrantes alemães representava certa autonomia para o conhecimento das escrituras bíblicas, no início do século XX, a ampliação dessa prática deveria garantir a máxima do republicanismo e contribuir para elevar o nível cultura da população.

\section{Referências}

ARENDT, Isabel Cristina. Educação, religião e Identidade étnica: o Allgemeine Lehrerzeitung e a escola evangélica no Rio Grande do Sul. São Leopoldo: Oikos, 2008. BAADE, Joel Haroldo. As escolas Teuto-brasileiras: uma aproximação ao tema. Professare. Santa Catarina, v. 1, p. 37-49, 2012.

BEZERRA, Holien Gonçalves. Conceitos básicos - Ensino de História: conteúdos e conceitos básicos. In: KARNAL, Leandro. (Org.) História na sala de aula: conceitos, práticas e propostas. $3^{\text {a }}$. ed. São Paulo: Contexto, 2005, p. 37-48.

BORGES, Maria Eliza Linhares. História \& fotografia. Belo Horizonte: Autêntica, 2011. BOTO, Carlota dos Reis. Pombalismo e Escola de Estado na História da Educação Brasileira. In: SAVIANI, Dermeval. (Org.). Estado e politicas educacionais na história da educação brasileira. Vitória: EDUFES, 2010, p. 107-152.

BRAUN, Felipe Kuhn. Novo Hamburgo - da fundação à emancipação política: 1824-1927. São Leopoldo: Oikos, 2012.

CELLARD, A. A análise documental. In: POUPART, J. et al. A pesquisa qualitativa: enfoques epistemológicos e metodológicos. Petrópolis, Vozes, 2008, p. 295-315. 
CORSETTI, Berenice.; LUCHESE, Terciane Ângela. Educação e instrução na Província do Rio Grande do Sul. In: GONDRA, José Gonçalves.; SCHNEIDER, Omar. (Org.). Estado e instrução nas províncias e na corte imperial. Vitória: EDUFES, 2010, p. 453-485.

CERTEAU, Michel de. A Cultura no Plural. Trad. Enid Abreu Dobránsky. 7ª . ed. Campinas, SP: Papirus, 2012.

DOSSE, François. História e Ciências Sociais. Trad. Fernanda Abreu. Bauru, São Paulo: Edusc, 2004.

DREHER, Martin N. Breve história do ensino privado gaúcho. São Leopoldo: Oikos, 2008.

DREHER, Martin N. Protestantismo de imigração no Brasil: sua implantação no contexto liberal-modernizador e as conseqüências desse projeto. In: DREHER, Martin N. Imigrações e história da Igreja no Brasil. Aparecida: Editora Santuário, 1993, p. 109-131.

FARIA FILHO, Luciano M.; VIDAL, Diana G. História da educação no Brasil: a constituição histórica do campo e sua configuração atual. Educação em Foco. Juiz de Fora, v. 17, n. 2, 2003, p. 28-47.

GIL, Natália de Lacerda. Os limites das estatísticas educacionais por aqueles que as produziram. In: XAVIER, Libânia.; TAMBARA, Elomar.; PINHEIRO FERREIRA, Antônio Carlos (Orgs.). História da Educação no Brasil: Matrizes interpretativas, abordagens e fontes predominantes na primeira década do século XXI. Vitória: EDUFES 2010, p. 193-217.

GIL, Natália de Lacerda; CALDEIRA, Sandra. Escola Isolada e Grupo Escolar: a variação das categorias estatísticas no discurso oficial do governo brasileiro e de Minas Gerais.

Estatística e Sociedade, Porto Alegre, p. 166-181, n. 1 nov. 2011.

GRUZINSKI, Serge. O historiador, o macaco e a centaura: a "história cultural" no novo milêmio. Estudos Avançados, vol. 17, nº. 49, São Paulo, p. 321-342, Set./Dez. 2003.

INÁCIO FILHO, Geraldo; SILVA, Maria Aparecida da. Reformas Educacionais Durante a Primeira República no Brasil (1889-1930). In: SAVIANI, Dermeval. (Org.). Estado e políticas educacionais na história da educação brasileira. Vitória: EDUFES, 2010, p. 217 250.

KREUTZ, Lúcio. A educação de Imigrantes no Brasil.In: LOPES, Eliane Marta Teixeira.; FARIA FILHO, Luciano Mendes.; VEIGA, Cynthia Greive. 500 anos de educação no Brasil. $4^{\text {a }}$. ed. Belo Horizonte: Autêntica, 2010a, p. 347-370.

KREUTZ, Lúcio. Práticas escolares entre imigrantes no Rio Grande do Sul: 1870-1940. In: GONÇALVES NETO, Wenceslau.; MIGUEL, Maria Elisabeth Blanck.; FERREIRA NETO, Amarílio. (Org.). Práticas Escolares e Processos Educativos: Currículo, Disciplinas e Instituições Escolares (Séculos XIX e XX). Vitória: EDUFES, 2010b, p. 307- 336.

KREUTZ, Lúcio. Escolas étnicas na história da educação brasileira: a contribuição dos imigrantes. In: STEPHANOU, Maria; BASTOS, Maria Helena Câmara, (Orgs.) História e memórias da educação no Brasil, vol. 2: século XIX. Petrópolis, RJ: Vozes, 2005, p. 150165. 
KREUTZ, Lúcio. Igreja Católica e processo escolar entre os imigrantes alemães católicos no Rio Grande do Sul. In: DREHER, Martin N. (Org.) 500 anos de Brasil e Igreja na América Meridional. Porto Alegre: EST, 2002, p. 472-480.

KREUTZ, Lúcio. Escolas comunitárias de imigrantes no Brasil: instâncias de coordenação e estruturas de apoio. Revista Brasileira de Educação, no 15, p.159 - 177, Set. /Out/Nov/Dez 2000 .

KREUTZ, Lúcio. A Escola Teuto-Brasileira Católica e a Nacionalização do Ensino. In: Nacionalização e imigração alemã. MÜLLER, Telmo. (Org.). Nacionalização e imigração alemã. São Leopoldo: Ed. UNISINOS, 1994, p. $27-64$.

KREUTZ, Lúcio. O professor paroquial: magistério e imigração alemã. Porto Alegre: Editora da Universidade; Florianópolis: EDUFSC; Caxias do Sul: EDUCS, 1991.

LOPES, Eliane Marta Teixeira.; GALVÃO, Ana Maria de Oliveira. História da Educação. Rio de Janeiro: DP\&A, 2001.

MAGALHÃES, Justino Pereira de. Tecendo nexos - História das instituições educativas. Bragança Paulista, SP: Edit. Universitária São Francisco - EDUSF, 2004.

MENDONÇA, Ana Waleska Pollo Campos. A Reforma Pombalina dos estudos menores (1759-1794) e o processo de profissionalização dos professores secundários no mundo lusobrasileiro. In: SILVA, Regina Helena.; CORREA, Rosa Lydia Teixeira.; MENDONÇA, Ana Waleska Pollo Campos (Orgs.). História da Profissão docente no Brasil. Vitória: EDUFES, 2010, p.37-58.

MÜLLER, Telmo Lauro. Colônia Alemã: 160 anos de história. Porto Alegre: Escola Superior de Teologia São Lourenço de Brindes, 1984.

MÜLLER, Telmo Lauro. Colônia Alemã: histórias e memórias. Caxias do Sul: UCS; São Leopoldo: Escola Superior de Teologia São Lourenço de Brindes, 1978.

RAMBO, Arthur Blásio. A Igreja dos imigrantes. In: DREHER, Martin N. (Org.) 500 anos de Brasil e Igreja na América Meridional. Porto Alegre: EST, 2002, p. 57-73

RAMBO, Arthur Blásio. A Escola comunitária teuto-brasileira católica. São Leopoldo: Unisinos, 1994.

SANTOS, Ademir Valdir Dos. Educação e Colonização no Brasil: as escolas Étnicas alemãs Cadernos de Pesquisa, v.42, n.146, p.538-561, maio/ago. 2012.

SAVIANI, Dermeval. O Estado e a promiscuidade entre o público e o privado na história da educação brasileira. In: SAVIANI, Dermeval. (Org.). Estado e políticas educacionais na história da educação brasileira. Vitória: EDUFES, 2010, p. 17-44.

SAVIANI, Dermeval. Instituições escolares no Brasil conceito e reconstrução histórica. In: MOURA NASCIMENTO, Maria Isabel et al. (Orgs.). Instituições escolares no Brasil: conceito e reconstrução histórica. Campinas, SP: Autores Associados: HISTDBR; Sorocaba, SP: UNISO, Ponta Grossa, PR: UEPG, 2007, p. 3-27;

SCHELBAUER, Analete Regina. As bases da construção do sistema educacional durante o Segundo Reinado (1850-1889). In: ROSSI, Ednéia Regina.;RODRIGUES, Elaine.; NEVES, 
Fátima Maria. (Orgs.). Fundamentos históricos da educação no Brasil. 2. ed. rev. e ampl. Maringá: Eduem, 2009, p.77-88.

SEYFERTH, Giralda. Memória coletiva, identidade e colonização: representações da diferença cultural no Sul do Brasil. MÉTIS: história \& cultura - v. 11, n. 22, p. 13-39, jul. /dez. 2012.

SOUZA, Rosa Fátima de. A organização pedagógica da escola primária no Brasil: do modo individual, mútuo, simultâneo e misto à escola graduada (1827 - 1893). In: GONÇALVES NETO, Wenceslau.; MIGUEL, Elisabeth Black.; FERREIRA NETO, Amarílio. (Org.). Práticas escolares e processos educativos: currículo, disciplinas e instituições escolares (séculos XIX e XX). Vitória, ES: EDUFES, 2011.

SOUZA, José Edimar de. As Escolas Isoladas: práticas e culturas escolares no meio rural de Lomba Grande/RS (1940-1952). 2015. 292 f. Tese (Doutorado em Educação) -- Universidade do Vale do Rio dos Sinos, Programa de Pós-Graduação em Educação, São Leopoldo, RS, 2015.

SOUZA, José Edimar de. Memórias de professores: histórias de ensino em Novo Hamburgo/RS (1940-2009). Porto Alegre: Evangraf, 2012.

SOUZA, José Edimar de; GRAZZIOTIN, Luciane Sgarbi Santos. Memórias de uma professora ao recompor cenários do ensino público em Lomba Grande, Novo Hamburgo, RS (1931-1942). Rev. Bras. Educ., Jun. 2015, vol.20, no.61, p.383-407.

http://dx.doi.org/10.1590/S1413-24782015206106

VALLE, Hardalla Santos do.; ARRIADA, Eduardo. A falta de homens de Letras: a educação no Continente de São Pedro do Rio Grande do Sul (1770-1834). Revista HISTEDBR On-line, Campinas, n.45, p. 36-48, mar. 2012.

VIÑAO FRAGO, Antônio; ESCOLANO, Agustín. Currículo, espaço e subjetividade: a arquitetura como programa. Tradução Alfredo Veiga-Neto. $2^{\mathrm{a}}$. ed. Rio de Janeiro: DP\&A, 2001.

WILLEMS, E. A aculturação dos alemães no Brasil. 2. ed. São Paulo: Nacional, 1980.

XAVIER, Itamaragiba Chaves. O projeto de Instrução Pública da República Rio-grandense (1836-1845). Revista Didática Sistêmica. Vol. 8, jul./dez. 2008, p. 281-294.

\section{Fontes}

MÜLLER, Osvald Henrich.[Usenraud]. Der erste Schullerer in Lomba Grande - Michael Paul-Gaspar. Arquivo Visconde de São Leopoldo. Fundo: Educação e Colégios. Grupo: caixa 1. Assuntos Escolares. 1 folha. S/a.

NOVO HAMBURGO. Jahresbericht der Deuthch = Evangelitchen Gemeinde Lomba Grande für 1928, p.1-4. Acervo particular da paróquia Evangélica de Lomba Grande [localizado em $2011]$. 
O 5 de Abril. Centenário da Comunidade Evangélica de Lomba Grande. Ano XXI, n. 47, Novo Hamburgo, 20 de fev. 1948.

PETRY, Leopoldo. O Município de São Leopoldo no ano do $1^{\circ}$ Centenário da independência do Brasil. Dados Históricos e Geográficos e estatísticos coligidos por Leopoldo Petry. Coletor Estadual de Novo Hamburgo. Ex-Secretário da Intendência Municipal de São Leopoldo. São Leopoldo, Porto Alegre, Cruz Alta, Ijuí: Rotermund \& Co, 1923.

SÃO LEOPOLDO. Atas da Câmara Municipal da Villa de São Leopoldo de 24 de julho de 1846 a 18 de dezembro de 1847. [Ata da Sessão Extraordinária da Câmara Municipal da Villa de São Leopoldo, 18 de set. de 1847, p. 216-219]. São Leopoldo-RS, 1846-1847. 